\title{
Developing a Learning Progression for Scientific Modeling: Making Scientific Modeling Accessible and Meaningful for Learners
}

\author{
Christina V. Schwarz, ${ }^{1}$ Brian J. Reiser, ${ }^{2}$ Elizabeth A. Davis, ${ }^{3}$ Lisa Kenyon, ${ }^{4}$ \\ Andres Achér, ${ }^{2}$ David Fortus, ${ }^{5}$ Yael Shwartz, ${ }^{5}$ Barbara Hug, ${ }^{6}$ Joe Krajcik ${ }^{3}$ \\ ${ }^{1}$ College of Education, Michigan State University, Erickson Hall, East Lansing, Michigan 48824 \\ ${ }^{2}$ Learning Sciences, Northwestern University, Evanston, Illinois \\ ${ }^{3}$ School of Education, University of Michigan, Ann Arbor, Michigan \\ ${ }^{4}$ Wright State University, Dayton, Ohio \\ ${ }^{5}$ Department of Science Teaching, Weizmann Institute of Science, Rehovot, Israel \\ ${ }^{6}$ College of Education, University of Illinois, Champaign, Illinois
}

Received 2 July 2008; Accepted 14 April 2009

\begin{abstract}
Modeling is a core practice in science and a central part of scientific literacy. We present theoretical and empirical motivation for a learning progression for scientific modeling that aims to make the practice accessible and meaningful for learners. We define scientific modeling as including the elements of the practice (constructing, using, evaluating, and revising scientific models) and the metaknowledge that guides and motivates the practice (e.g., understanding the nature and purpose of models). Our learning progression for scientific modeling includes two dimensions that combine metaknowledge and elements of practice-scientific models as tools for predicting and explaining, and models change as understanding improves. We describe levels of progress along these two dimensions of our progression and illustrate them with classroom examples from 5th and 6th graders engaged in modeling. Our illustrations indicate that both groups of learners productively engaged in constructing and revising increasingly accurate models that included powerful explanatory mechanisms, and applied these models to make predictions for closely related phenomena. Furthermore, we show how students engaged in modeling practices move along levels of this progression. In particular, students moved from illustrative to explanatory models, and developed increasingly sophisticated views of the explanatory nature of models, shifting from models as correct or incorrect to models as encompassing explanations for multiple aspects of a target phenomenon. They also developed more nuanced reasons to revise models. Finally, we present challenges for learners in modeling practices_-such as understanding how constructing a model can aid their own sensemaking, and seeing model building as a way to generate new knowledge rather than represent what they have already learned. (c) 2009 Wiley Periodicals, Inc. J Res Sci Teach 46: 632-654, 2009
\end{abstract}

Keywords: scientific modeling; learning progression; scientific practice; student learning

Research-based reforms in science education have emphasized the importance of engaging learners in scientific practices-social interactions, tools, and language that represent the disciplinary norms for how scientific knowledge is constructed, evaluated, and communicated (Duschl, Schweingruber, \& Shouse, 2007). Involving learners in developing and investigating explanations and models leads to more sophisticated understanding of key models in science, as well as helping learners understand the nature of disciplinary knowledge (e.g., Lehrer \& Schauble, 2006). Yet, scientific practices require shifts in traditional classroom norms that involve learners in knowledge building and negotiation (Berland \& Reiser, 2009;

Contract grant sponsor: National Science Foundation; Contract grant numbers: ESI-0628199, ESI-0439352, ESI-0439493.

Correspondence to: Dr. Christina V. Schwarz; E-mail: cschwarz@msu.edu

DOI 10.1002/tea.20311

Published online 7 July 2009 in Wiley InterScience (www.interscience.wiley.com). 
Jimenenez-Aleixandre, Rodriguez, \& Duschl, 2000; Lemke, 1990). For effective participation in scientific practices, teachers and students need support with the practices as well as with the scientific ideas addressed by the practice (Duschl et al., 2007).

The MoDeLS project, Modeling Designs for Learning Science, is developing a learning progression to represent successively more sophisticated levels of engagement in and knowledge of scientific modeling practices. Our goal is to make this core scientific practice accessible and meaningful for learners in the upper elementary and middle grades. A scientific model is an abstract, simplified, representation of a system of phenomena that makes its central features explicit and visible and can be used to generate explanations and predictions (Harrison \& Treagust, 2000). Involving learners in modeling practices can help them build subject matter expertise, epistemological understanding, and expertise in the practices of building and evaluating scientific knowledge (Lehrer \& Schauble, 2006; Lesh \& Doerr, 2000; Schwarz \& White, 2005; Stewart, Cartier, \& Passmore, 2005). The opportunity to engage in scientific modeling is central in developing and evaluating explanations of the natural world.

Scientific modeling, however, is rarely incorporated into educational experiences of elementary or middle school students. When use of models occurs, it is often reserved for older learners and primarily used for illustrative or communicative purposes, thus limiting the epistemic richness of the scientific practice (Windschitl, Thompson, \& Braaten, 2008). Indeed, educators lack high-quality curriculum materials that support the use of scientific modeling. Furthermore, supporting scientific modeling in the classroom places high demands on teachers. Many teachers have limited experience with scientific modeling and lack knowledge of students' ideas about the practice (Harrison \& Treagust, 2000; Justi \& Gilbert, 2002). Teachers often see models as useful for teaching about science content, but not about the nature of science (Henze, Van Driel, \& Verloop, 2007; Justi \& Gilbert, 2002). Preservice teachers tend to view modeling through the more familiar lens of the scientific method (Windschitl et al., 2008). Thus, many science teachers need support to effectively engage their students in scientific modeling.

Effective designs for science learning require considering which aspects of expert practice are productive for learners. Our goal is to develop a learning progression that characterizes the aspects of modeling that can be made accessible and meaningful for students and teachers. In this article, we outline our work toward the development of a learning progression for scientific modeling, including the theoretical development aimed at articulating and unpacking a version of the target practice (derived from prior work and the literature), and empirical explorations that help identify the successes and challenges in understanding and participating in the modeling practice. This learning progression contrasts with other work (e.g., Smith, Wiser, Anderson, \& Krajcik, 2006), in that the primary focus of this progression is a scientific practice rather than specific scientific ideas such as the nature of matter. We use the empirical results of attempts to support modeling practice to identify aspects of the practice that can be made tractable for students, and to identify areas of challenge. We consider the following questions:

1. What aspects of modeling practice can be made meaningful and productive for science learners?

2. What successes and challenges emerge when students engage in modeling practices?

\section{Defining Scientific Models and Modeling}

Our view of modeling practice draws on areas of agreement in current studies of learning about modeling (Harrison \& Treagust, 2000; Lehrer \& Schauble, 2006; Lesh \& Doerr, 2003). We define a scientific model as a representation that abstracts and simplifies a system by focusing on key features to explain and predict scientific phenomena. Examples of scientific models include the Bohr model of the atom, the particle model of matter, a light ray model for how we see objects, the water cycle model, and a food web model indicating interactions between organisms. In the framework for modeling presented by Lesh and Doerr (2003, p. 10), a model consists of "elements, relations, operations, and rules governing interactions that are expressed using external notation systems." The elements are the conceptual elements used to represent important aspects of phenomena. Observations about the phenomena yield candidate ideas about the elements, relations, operations, and rules within the model. The model must be consistent with the data collected about the phenomena. 
Models are also generative. One reasons with models to explain and predict natural phenomena. A model provides an explanation for why the phenomenon behaves in the way it does, and can generate new predictions that can be tested against new data from the phenomena. The model and the phenomenon exist in a dialogic relationship; analyses of the phenomenon gives insights into potential elements, relations, operations, and rules within the model, and indicates the evidence that constrains possible models. In turn, the model generates new explanations and predictions about the behavior of the phenomenon. It is important to clarify that not all representations are models. Models are specialized representations that embody aspects of mechanism, causality, or function to illustrate, explain, and predict phenomena.

Working with scientific models involves constructing and using models, as well as evaluating and revising them. For example, to investigate the question "What causes a shadow?" students could construct an initial model including a picture of a shadow caused by light shining on an object. They might then investigate conditions needed to produce shadows, motivated by questions that arose when trying to figure out what to put into their diagrams. Those data would be analyzed for patterns and used as evidence to support or reject aspects of the model. The model could be refined to include a surface on which the shadow is projected and a light source that emits direct light rather than diffuse light, as well as an unblocked path for the light to travel. After revising those models to account for patterns in data and to include learned scientific constructs such as light traveling as light rays (see Figure 1), those models could generate multiple explanations for other phenomena such as why clouds sometimes make shadows or the most effective ways to play shadow tag. Engaging learners in modeling practice enables them to revise their own conceptual models and to use those revised models in reasoning.

Unpacking the Learning Goals: Core Commitments in Developing the Learning Progression

Scientific modeling is a rich practice, and contains many candidate aspects in which designers might choose to involve learners. The first step in crafting the learning progression is to "unpack" the learning goals, drawing out the implicit understandings they entail (Krajcik, McNeill, \& Reiser, 2008), and organizing them in a coherent framework. There are two important commitments in our learning progression designthe integration of the metaknowledge and elements of the practice, and the integration of sensemaking and communicative aspects of the practice.

\section{Integration of Metamodeling Knowledge and Elements of the Practice}

Our first central commitment is the weaving together of engaging in the practice-the elements of the practice-with the knowledge that underlies it and makes it meaningful. Involving learners in meaningful participation with the practice requires that they understand the rationale and norms that govern the practice (i.e., what are they doing and why are they doing it). It is therefore important that they acquire an understanding of the roles of models and modeling in science. This knowledge about modeling is a type of nature of science understanding (Lederman, 2007) that we refer to as metamodeling knowledge (Schwarz \& White, 2005). Learners need to understand how models are used, why they are used, and what their strengths

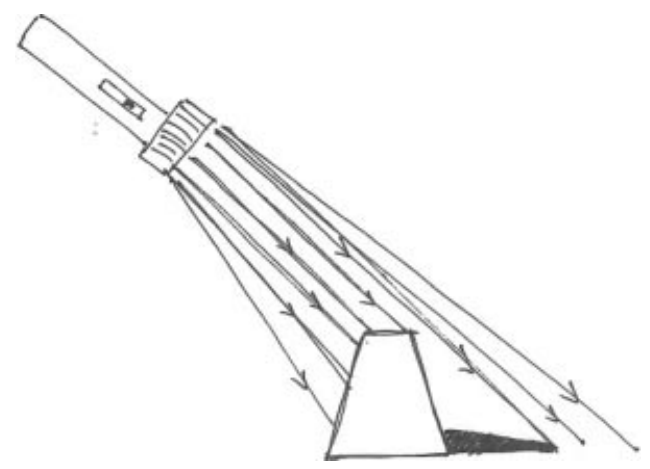

Figure 1. Example model of how shadows occur. 
and limitations are, in order to appreciate how science works and the dynamic nature of knowledge that science produces (Abd-El-Khalick et al., 2004).

We argue that the elements of the practice and the metaknowledge should not be viewed as separate learning goals. The practice and underlying knowledge are significantly more powerful and meaningful when addressed with one another rather than as separate components. It would be a poor version of the practice if students were to engage in the steps of the practice by rote rather than understanding the purpose of each step, or strive to achieve models of particular forms without understanding why those characteristics of models are important. Similarly, it would be of little practical use for students to learn abstract decontextualized understandings about science, where they could describe the nature or purpose of models, without being able to use these understandings in guiding their development and use of models. Therefore, our learning progression specifies the aspects of metaknowledge that influence the elements of the practice, and we attempt to support and analyze growth in the interaction of metaknowledge and these elements of practice.

Building on prior work on epistemologies and the nature of science (Carey \& Smith, 1993), and student learning about modeling (Grosslight, Unger, Jay, \& Smith, 1991; Snir, Smith, \& Raz, 2003; Spitulnik, Krajcik, \& Soloway, 1999; Stewart et al., 2005), we have operationalized the practice of modeling to include four elements that we target:

- Students construct models consistent with prior evidence and theories to illustrate, explain, or predict phenomena.

- Students use models to illustrate, explain, and predict phenomena.

- Students compare and evaluate the ability of different models to accurately represent and account for patterns in phenomena, and to predict new phenomena.

- Students revise models to increase their explanatory and predictive power, taking into account additional evidence or aspects of a phenomenon.

These elements are consistent with design-based practices (e.g., design, test, and revise, Fortus, Krajcik, Dershimer, Marx, \& Mamlok-Naaman, 2005) and mathematical modeling practices (e.g., describe, manipulate, translate, and verify, Lesh \& Doerr, 2003).

We suggest that it is crucial to involve learners in the construction of models, rather than primarily working with models provided by teachers or scientific authorities. The pedagogical benefits of working with scientific models rests critically on having students develop models to articulate their own understanding of how a scientific phenomenon behaves (Acher, Arcà, \& Sanmartí, 2007; Schwarz \& White, 2005; Wilensky \& Reisman, 2006; Windschitl et al., 2008). Furthermore, we hypothesize that the process of revising models that learners themselves have constructed to reflect advances in their understanding is more effective than traditional uses of models in helping the learners understand the need to evaluate models and improve them in light of new findings. Finally, we argue that constructing and evaluating models are the least typical uses of models in schools, where models such as physical simulations (e.g., a stream table) or computational models or visualizations are used to help students see how phenomena behave, rather than as ongoing attempts to capture and then improve on explanations of phenomena (Schwarz \& Gwekwerere, 2007).

Metamodeling knowledge guides the practice by helping students engage in the practice-for example, enabling students to more effectively plan and evaluate their investigations. Knowing the forms and purposes of models and criteria for evaluating them can help guide learners in more successful and reflective use of models in scientific reasoning (Schwarz, 2002; Schwarz \& White, 2005); thus, metamodeling knowledge is integrally connected to the elements of modeling practice. We distinguish the metamodeling knowledge from the elements of modeling practice for instructional purposes, to foreground the epistemological dimensions that are often tacit in instructional settings.

A related issue in the connection between metaknowledge and practice is the role of specific domains of scientific phenomena (such as the nature of matter or ecosystem dynamics) in the progression. The influence that specific contexts have on learning scientific practices is, of course, critical (Lehrer \& Schauble, 2006; Tabak \& Reiser, 2008). However, our learning progression focuses on the practice of scientific modeling itself, rather than on how particular ideas are developed (such as the particle nature of matter or a systems model of interactions in ecosystems). In particular, this learning progression characterizes how the practice of 
modeling itself can become more sophisticated with appropriate learning experiences. Thus, we look not only for improved content in particular models, but for changes in how the modeling itself is being done. Our intent is not to minimize the importance of learning specific scientific models. Nor do we intend to minimize the challenges of generalizing understandings about what it means to build a successful model developed in one scientific context, such as modeling the interactions of light and material objects, to apply to another situation, such as modeling how particles travel through air. In fact, our goal is to explore to what extent knowledge about modeling can be abstracted from the specific modeling contexts in which it is developed. A commitment to examine ways knowledge may carry from one setting to another is important if we are going to look for learning about this practice, which can be applied across a wide range of kinds of models and scientific phenomena.

As a starting point in characterizing the important metamodeling knowledge, we have drawn on empirical studies of modeling (Schwarz \& White, 2005) and epistemic understandings (Abd-El-Khalick et al., 2004; Lederman, 2007), and on standards documents (AAAS, 1993). This metamodeling knowledge includes understanding the purpose of scientific models, their nature, and criteria for evaluating them (see Table 1). In particular, learners should understand the purpose of models and modeling as powerful tools and practices for advancing our knowledge about the world. For example, models can be used to represent scientific phenomena that are too complex or difficult to observe directly and they enable us to predict and explain natural phenomena. Second, models are abstractions, not literal representations, and multiple models are possible. Finally, models are evaluated and revised based on empirical evidence and theoretical argument to improve their predictive and explanatory power. There is much overlap between these potential dimensions of metamodeling knowledge, particularly between understandings about nature of models and purpose of models. We have collapsed these dimensions into two in our learning progression, as we detail below.

\section{Sensemaking and Communication}

Our second commitment in developing our learning progression recognizes that models can be used to help scientists and learners generate new understandings or communicate their understandings to othersand often are used for both purposes. These two aspects are related, mutually supportive, and often occur simultaneously (see Figure 2), although one or the other may be foregrounded at a particular time. The distinction between sensemaking and communication refers to the primary audience for whom the learners are creating the model. When sensemaking, individuals or groups are making a model for themselves, to try to understand a phenomenon, articulating their understanding as an expressed model to help clarify their thinking and develop group consensus. For communication, the learners are at the point where they are ready to share their ideas with others, articulating their model to see if others agree, try to persuade others or help them understand the phenomena.

Table 1

Candidate components of metamodeling knowledge for a learning progression for modeling

Nature of models

Models can represent non-visible and non-accessible processes and features

Different models can have different advantages

Models are representations that have limitations in what they represent about phenomena

Models can be changed to reflect growing understanding of the phenomena

There are multiple types of models: diagrams, material models, simulations, etc.

Purpose of models

Models are sense-making tools for constructing knowledge

Models are communication tools for conveying understanding or knowledge

Models can be used to develop new understandings, by predicting new aspects of phenomena

Models are used to illustrate, explain, and predict phenomena

Criteria for evaluating and revising models

Models need to be based on evidence about the phenomena

Models need to include only what is relevant to their purpose 


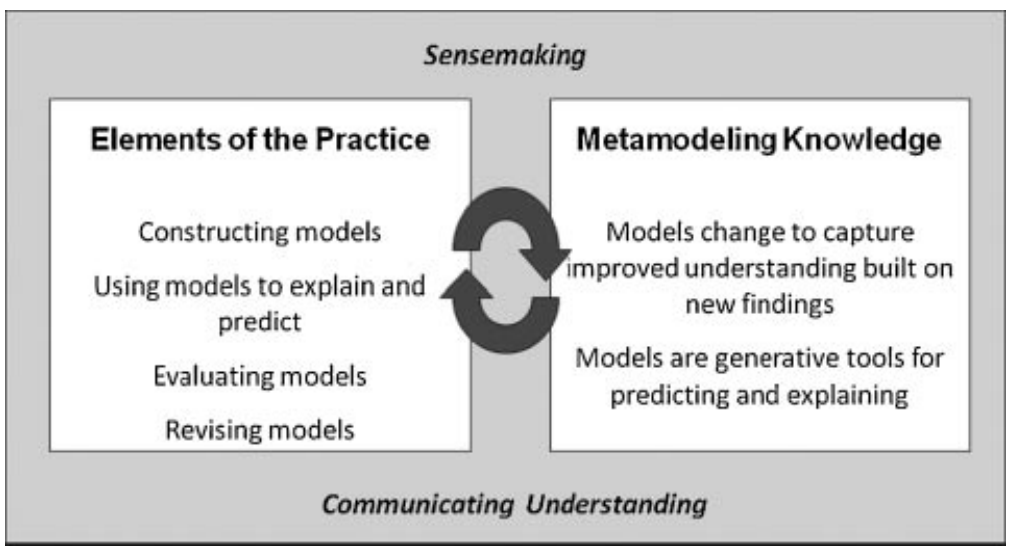

Figure 2. Modeling practice as the interaction of the elements of the practice and metamodeling knowledge. The two types of goals, sensemaking and communicating understanding, each emerge from the use of the practice elements and metamodeling knowledge.

This distinction is important in identifying model practices that go beyond common classroom science practice. Typically, classroom practice uses models for communication of (finalized) ideas, rather than for sensemaking around developing ideas. Furthermore, constructing models as supporting sensemaking (helping the modelers figure out a phenomenon) is new to most teachers, who think of models created by students as ways to demonstrate understanding they have acquired in another context (Schwarz \& Gwekwerere, 2007). Often, if students need to learn about phenomena, teachers assume that models should be provided to them to observe and sometimes manipulate (such as stream tables or computer models) where the accuracy of the model is not questioned nor do students attempt to improve the model.

\section{Developing a Learning Progression with Empirical Support}

The goal of this article is to present a proposed learning progression, organized around two dimensions, each of which integrates practice and metamodeling knowledge. We refer to these key integrative dimensions as "Models as generative tools for predicting and explaining" and "Models change as our understanding improves." We present illustrations of student performance and understanding along each of these dimensions drawn from several empirical investigations involving elementary and middle school students. We use excerpts from these data, which include written assessments of student reasoning with models, reflective interviews about modeling practice, and classroom discourse during modeling activities, to identify aspects of performance and understanding that are evidenced in students' work, and those which may not be achieved. The data help elucidate the meaning of the dimensions of the progression, and help distinguish between various levels of performance. The data are not intended as a test of a particular curriculum or teaching approach, or an overall validation of the progression. Rather, the data help illustrate what kinds of performances and understandings in modeling are possible with elementary and middle grades students, with appropriate support, and how they can be characterized using the learning progression.

\section{Context for the Learning Progressions Work}

Before describing the dimensions of our learning progression, we first provide a brief description of the contexts of our work. Our research has taken place in several elementary and middle school classrooms. Illustrations in this article come from 5th and 6th grade classrooms.

In the elementary level, we designed a 6-week unit for 5th grade students around modeling evaporation and condensation phenomena, using a solar still as an anchoring phenomenon. A solar still is a device that can distill or purify water using the sun as a heat source. In the device, water evaporates into the air and condenses on a surface from which it is collected and used as clean drinking water. The unit was designed to engage students in the modeling practices of constructing, evaluating, revising, and using scientific models of 
Table 2

Instructional modeling sequence for elementary curriculum materials

\begin{tabular}{ll}
\hline Sequence & \multicolumn{1}{c}{ Description } \\
\hline Anchoring phenomena & $\begin{array}{c}\text { Introduce driving questions and phenomena for a particular concept. Use a } \\
\text { phenomenon that may necessitate using a model to figure it out. } \\
\text { Create an initial model expressing an idea or hypothesis. Discuss purpose and } \\
\text { nature of models. } \\
\text { Investigate the phenomena predicted and explained by the model. } \\
\text { Empirically test the model }\end{array}$ \\
$\begin{array}{l}\text { Evaluate the model } \\
\text { evaluation and revision. }\end{array}$ \\
$\begin{array}{l}\text { Test the model against other ideas } \\
\text { Revise the model }\end{array}$ & $\begin{array}{c}\text { Change the model to fit new evidence. Compare competing models, and construct } \\
\text { a consensus model. } \\
\text { Use the model to predict or explain }\end{array}$ \\
\hline
\end{tabular}

evaporation and condensation phenomena to explain how the solar still works and how other evaporation and condensation phenomena occur (see Table 2 for an outline of our general instructional sequence). In particular, students construct and revise a model of evaporation and, later, a model of condensation based on empirical evidence of the presence of water vapor in the air. They use newly introduced ideas of water as being composed of smaller bits or particles that spread out in the air so that they cannot be seen (evaporation) and clump together into larger bits of water drops (condensation) under particular conditions. Students' expressed models take the form of written diagrams. The modeling practices within the unit are infused with metamodeling conversations at key moments when epistemic issues are the most relevant (e.g., discussing the evaluation of models when comparing and contrasting different models for the process).

The elementary classrooms sites were located in two different Midwestern US cities (for more detail on these studies, see Kenyon, Schwarz, Hug, \& Baek, 2008). Illustrations in this article are derived from schools that were ethnically and linguistically diverse in middle to upper-middle class suburban districts. All teachers had 7 or more years of teaching experience and were new to using this unit. Individual and small group modeling-specific professional development was provided before and during the enactments.

At the middle school level, students were engaged in modeling as they studied two units that are part of the Investigating and Questioning our World Through Science and Technology (IQWST) project (Krajcik et al., 2008; Shwartz, Weizman, Fortus, Krajcik, \& Reiser, 2008). Scientific modeling is the central scientific practice used in the IQWST 6th grade physics and chemistry units. These 6-week units, organized around driving questions that provide a context to motivate and apply the science students learn, involve students in creating models to explain phenomena and then revising models to account for new findings. These units draw on the same types of activities shown in Table 2. The 6th grade physics unit, Can I Believe My Eyes?, focuses on investigating how light provides us information about the world. The central modeling goal is for students to explain how the interaction of light, physical objects, and a sensor (e.g., our eyes) allows us to see objects. The 6th grade chemistry unit, How Can I Smell Things from a Distance?, builds on students' experience with models and modeling in the 6th grade physics unit on light. The main content learning goal is to develop a particle view of matter. As in the physics unit, students are asked to construct models and use them to explain how we smell something from across a room. In addition, the chemistry unit introduces the idea of multiple possible models representing the same phenomenon.

The middle school classrooms studied are also in two Midwestern US cities (different from the cities in the elementary studies). These classrooms were located in urban and suburban schools piloting IQWST 6th grade materials in 2006-2007. Each teacher was teaching the unit for the first or second time. The focus group analysis was conducted in one suburban school during their enactment of the IQWST chemistry unit, following their enactment of the physics unit. The three focus groups came from different classrooms taught by the same teacher who was teaching the unit for her second time. Excerpts reported on in this article are derived from nine focus group interview sessions throughout the chemistry unit. 


\section{Two Dimensions of a Learning Progression for Scientific Modeling}

We represent our learning progression for scientific modeling as a set of related construct maps of progress variables, each of which shows levels of performance and understanding (Wilson, 2005). Each progress variable for modeling represents a trajectory of more complex aspects of this practice and its associated understandings that we expect students to exhibit in classroom modeling activities. Each level of performance within a variable represents a more sophisticated version of the previous level of performance.

We organize these performances and understandings in two dimensions, each of which incorporates the four elements of practice and the metamodeling knowledge that guides the practice. The two dimensions concern the generative nature of models as tools for explaining and predicting, and the dynamic nature of models as improving with new understanding. These dimensions have emerged as more useful than organizing the analyses of the level of students' performance according to the four elements of practice (i.e., construct, use, evaluate, and revise). These elements of practice are typically overlapping (e.g., evaluating various candidate models while constructing them) and we found that each was informed by similar metamodeling knowledge. Instead, we identified two clusters of issues in understanding models that influence all four elements of practice. The generativity of models dimension organizes understandings about how models explain new aspects of phenomena, and is useful in guiding what kinds of models to create and ways to evaluate and then revise them. The dynamic nature of models dimension organizes understandings about when models need to change, and thus guides model construction, evaluation, and revision.

These two dimensions reflect the core commitments described earlier. Each dimension attempts to characterize reflective practice- the combination of students' performance of the task (both process and product), accompanied by the underlying metaknowledge that makes the activity meaningful. Thus, the construct map analyzes the modeling process students exhibit (such as the decisions they make about revising models), their reasoning products (such as properties of their constructed models or types of changes in a revised model), and their understanding of these performances (as reflected in their discourse or written explanations). The dimensions also bring together both sensemaking and communication, referring at each level to the role the model plays in making sense of phenomena, and to considerations of communicating understandings to persuade and help others understand the model's explanations.

Refining these two dimensions of the learning progression is an iterative process. We use the two construct maps as a framework to explore the nature of students' performances and understandings about modeling. The construct maps enable us to tease apart successful understandings and emerging challenges. Analyses of students' understandings about their modeling practices help uncover important aspects that may need to be captured in the construct maps.

\section{Models as Generative Tools for Explaining and Predicting}

The first dimension of the learning progression, models as generative tools for explaining and predicting, addresses one of the main characteristics of scientific models: that they are productive tools for generating and representing explanations and predictions about scientific phenomena. This dimension builds on prior work on levels of students' understanding of the nature of models (Carey \& Smith, 1993), which emphasizes that the purpose of model construction is to develop and test ideas. This dimension also builds on literature exploring the nature of science, which emphasizes understanding theories as tools to advance knowledge by generating hypotheses, and understanding the role of theories in guiding observation and interpretation of findings (Lederman, 2007).

In order to describe levels of students' reflective practice along this dimension, we focus on how students construct and use models to understand scientific phenomena, what students consider important to capture in models (e.g., mechanisms, processes), and whether students view models as useful for advancing their own knowledge as well as helping communicate what has been learned to others. Table 3 presents our proposed learning progression for this dimension. Each of the four levels is shown with two related performances that exemplify the level. First, we describe each level with examples that show how it is realized in students' classroom work and the associated understandings. Then we describe some of the changes learners exhibit as they are engaged in modeling practices. 
Table 3

A learning progression for understanding models as generative tools for predicting and explaining

Level Performances

4 Students construct and use models spontaneously in a range of domains to help their own thinking.

Students consider how the world could behave according to various models. Students construct and use models to generate new questions about the behavior or existence of phenomena.

$3 \quad$ Students construct and use multiple models to explain and predict more aspects of a group of related phenomena.

Students view models as tools that can support their thinking about existing and new phenomena. Students consider alternatives in constructing models based on analyses of the different advantages and weakness for explaining and predicting these alternative models possess.

2 Students construct and use a model to illustrate and explain how a phenomenon occurs, consistent with the evidence about the phenomenon.

Students view models as a means of communicating their understanding of a phenomenon rather than a tool to support their own thinking.

$1 \quad$ Students construct and use models that show literal illustrations of a single phenomenon.

Students do not view a model as tool to generate new knowledge, but do see models as a means of showing others what the phenomenon looks like.

\section{Empirical Illustrations of the Levels of Performance}

At Level 1, students construct and use models that show literal illustrations of a single phenomenon, depicting only observable features, rather than attempting to explain the phenomenon. Students at this level view models as a means of describing the phenomenon to others, rather than explaining why it occurs. This initial level can be seen in many of the elementary students' initial modeling process, and in some aspects of middle school students' work. For example, Figure 3 shows an elementary student's initial model of evaporation, which includes a drawing of water on a plate and water dried out on the plate. Additionally the initial model in Figure 4 reflects the beginnings of a move beyond Level 1 in the inclusion of nonvisible light rays along with the visible feature such as the light source, object, and shadow. But the model lacks any

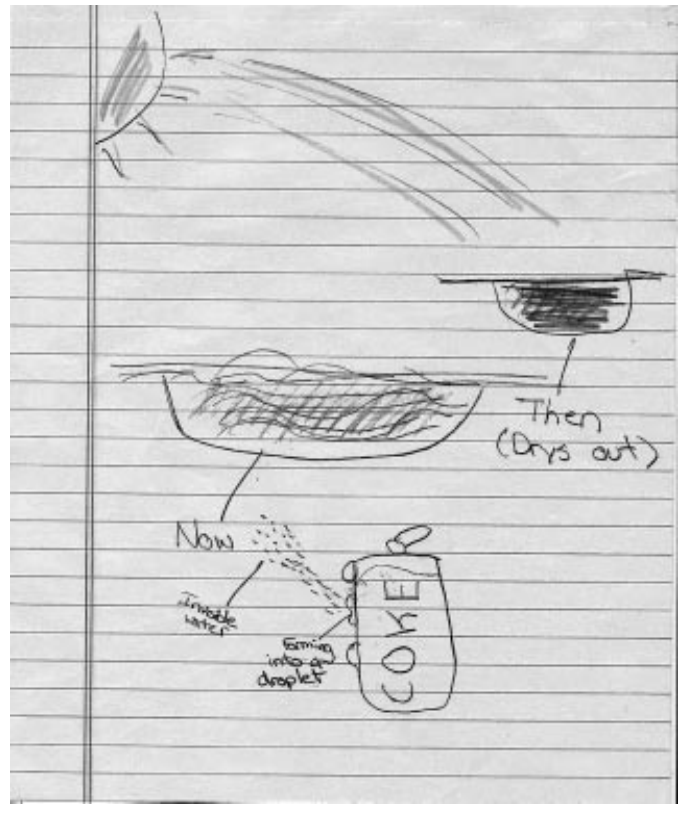

Figure 3. A 5th grade student's pre-interview evaporation and condensation model. 
representation of how the light rays are involved in the creation of the shadows. Some students talk about models in ways that are consistent with Level 1. For example, one student studying condensation stated, "A model would [be] like an actual Coke can with water on the side, or a picture of it, that is more detailed and colored ...." Students view the purpose of constructing and using models at this level as duplicating reality and illustrating one correct idea. For example, one student stated, "One of those models are the right prediction, and it really could happen in the real world."

Level 2 embodies the notion that students construct and use a model to explain how a phenomenon occurs, and this model is consistent with evidence about the phenomenon. These explanations might include non-observable processes, mechanisms, or structural components that help to explain the phenomenon. Students also consider observational or experimental evidence as well as authoritative evidence from the teacher, textbook, or other sources. Furthermore, students at this level view models as a means for communicating their understanding of a phenomenon. However, they do not yet see models as tools to support their own thinking.

This level of the progression was often reflected in students' performance. For example, many students at the elementary level began to incorporate non-observable qualities in their models as they learned more about modeling and about evaporation and condensation. Such aspects frequently included microscopic particles, arrows showing where water or water vapor is moving, and phrases to describe the process. The post-response in Figure 5 illustrates these aspects. This 5th grade student's post-model compared to the premodel in Figure 3 includes explanations such as "particles in the air are attracting and bonding together" and "the molecules in the air bonded together to form droplets on the side of them." The representation itself also indicates change over time, using arrows and explaining "how" the water disappears from the plate and condenses on the soda can. Similarly, the 6th grade student's final model in Figure 6 compared to the initial model in Figure 4 shows the shadow as a less illuminated portion of another object (the ground), caused by the object blocking the light rays. The model also shows how light is reflected from the object as well as absorbed and scattered. Students refer to the explanatory nature of the model their assessments and interviews. For example, one 5th grade student wrote that something is a model "because it just doesn't show a picture or a diagram. ... It explains the kinetic energy. It explains the molecules in the air, and the particles vibrating. It doesn't just show it, it explains." This student explicitly rejects the Level 1 notion of veridical illustration of the phenomenon that was more common in these students' initial models.

Level 3 adds complexity in several aspects of modeling. The level brings a focus not only on explaining observed phenomena but also on generating predictions about new phenomena related to what they have studied. In addition, at this level students' models explain a cluster of related phenomena, and this may require constructing multiple models. Students may consider alternatives in constructing models, evaluating the advantages and weaknesses of the models for explaining and predicting phenomena.

To illustrate Level 3, we use a typical example of a model in which a student drew explicitly on prior models to extrapolate to new phenomena, suggesting that the student sees the model as useful for explaining new phenomena. Figure 7 is an elementary student's model showing how the water is evaporating from the dirty water and moving toward the top of the solar still. This model shows the student applying an understanding of evaporating particles and water molecule movement. This model includes arrows and

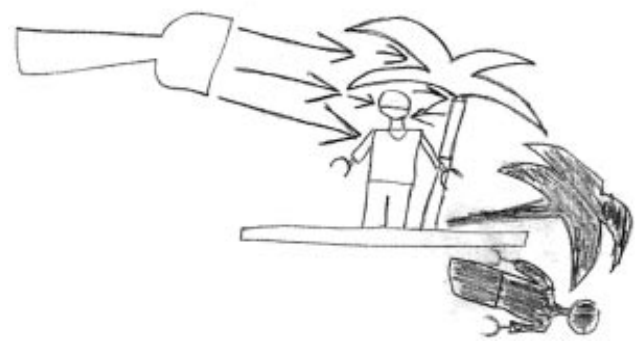

Figure 4. A 6th grade students' initial model of how shadows are made and seen (from Weizman \& Fortus, 2007). 


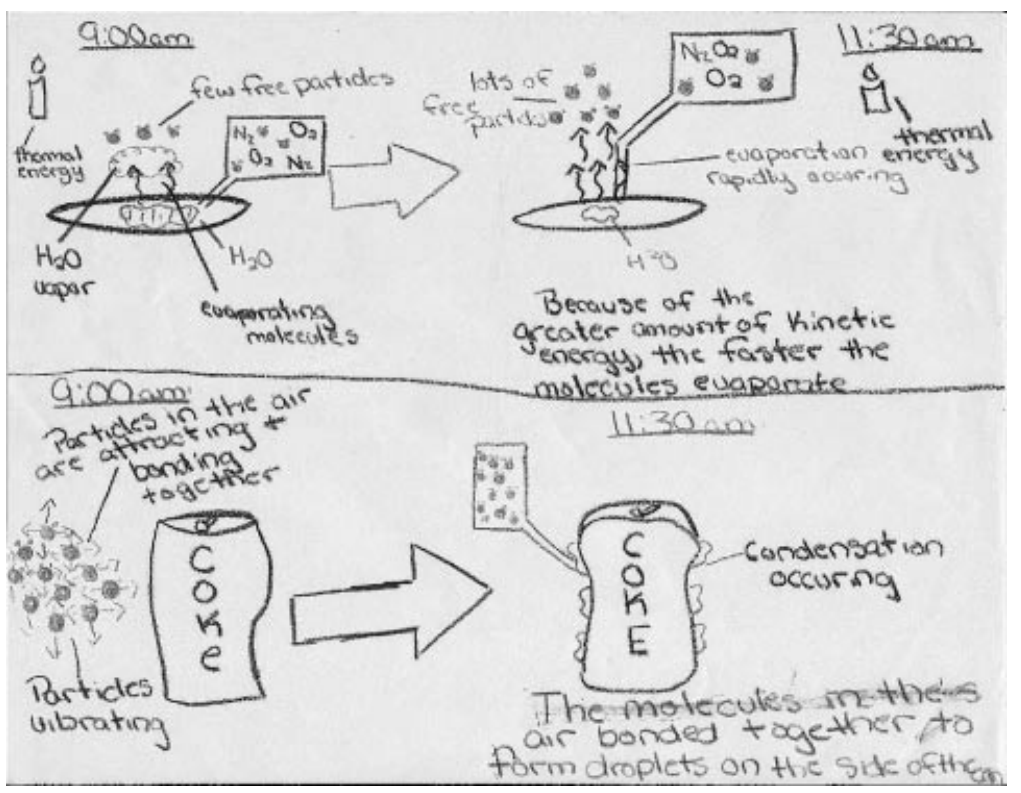

Figure 5. A 5th grade student's post-interview evaporation and condensation model compared to the pre-model in Figure 3.

labels, indicating the movement to the top of the still, and moisture collecting on the side and top of the still. Thus, like Level 2 performances, this model includes an explanatory mechanism to account for the observed results (how the water got to the underside of the plastic wrap), but it applies the explanatory mechanism to a new phenomenon (the solar still). This diagram reveals how the student drew explicitly on their prior models in constructing an explanation and prediction for a new but somewhat familiar phenomenon.

We see these aspects of Level 3 in elementary students' written post-tests, as students apply explanatory models learned in one context to explain new (but related) phenomena. For example, students were asked to "use one of the models you drew to explain what happens to your color marker when you leave the top off of it

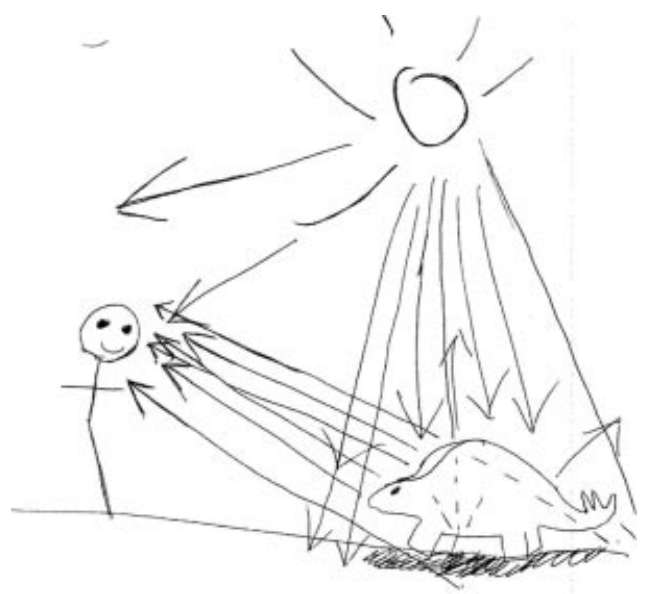

Figure 6. A 6th grade students' final model of how shadows are made and seen compared to the initial model in Figure 4 (from Weizman \& Fortus, 2007). 


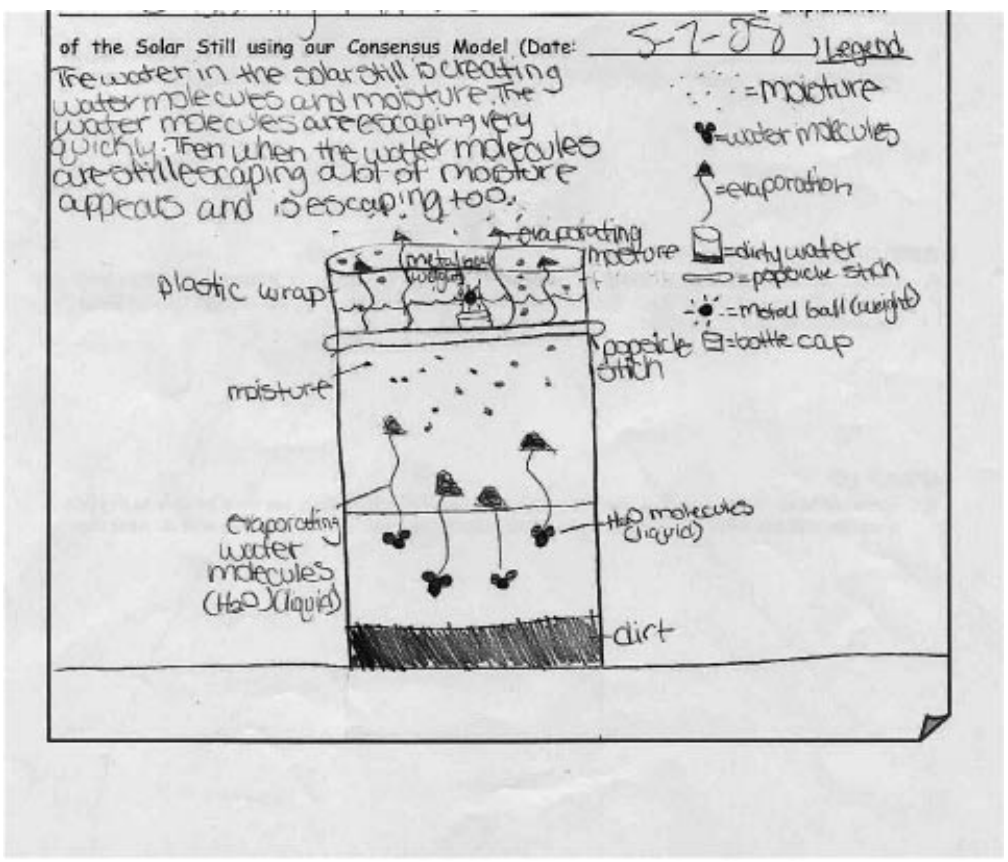

Figure 7. Student using their model of evaporation and condensation to explain the solar still.

for a week." One student wrote, "In the model of the cup with no lid, the water is evaporating into water vapor or gas, and that's what happens with the marker because it's a liquid and all liquids evaporate into a gas or water vapor."

Some 6th grade students also exhibited Level 3 reflective practice in their focus interviews when they applied their model beyond the examples they used to construct it. The following interactions illustrates this type of understanding:

Researcher: Could a model like the models you have done help you to understand something that you don't know yet? Just to predict?

Sean: Yes that we could use these models to show about a different gas. Because I think air is also a type of gas. So if we know what air does and has in it and how it moves when other things come in its way and everything, we could find out what other gases also do because they could be similar to air. [Interview \#5, Lesson 4]

Finally, the Level 3 consideration that models need to explain multiple related aspects of a phenomenon can be seen in some 6th grade students' discussions of how their models connect to their investigations. For example, one student has drawn two related models, one to explain how air can be compressed into a smaller space, and one to explain how it can expand to fill more space, but draws on the same underlying explanatory model, namely the existence of empty space between moving air particles. In discussing the models, she states:

Well, we're probably drawing different models because, when the plunger part of the syringe is out, there's going to be a different activity with the air going on than when the air's compressed and when the plunger is farther down toward the tip. [Interview \#5, Lesson 4]

Level 4 in this dimension reflects the goal that students construct and use models spontaneously in a range of domains to help their own thinking. Students consider how the world could behave according to 
various models, and they construct and use models to generate new questions about the behavior of phenomena. This focus on developing questions has not emerged in our own classroom trials, perhaps due to the constraints of school science in which the curriculum and teacher have a strong hand in guiding students into particular questions. However, using models to advance scientific knowledge by generating questions to guide research is fundamental to understanding knowledge building in science (Carey \& Smith, 1993; Lederman, 2007; Lehrer \& Schauble, 2006).

\section{Shifts among Generative Levels in the Elementary Students}

Our research uncovered evidence that elementary learners engaged in our modeling curriculum shifted between levels of our learning progression-primarily from displaying characteristics of Level 1 to displaying more characteristics of Level 2. Prior research suggested that the distinction between illustrative pictures and more abstract explanatory models can be a challenge for younger students (Carey \& Smith, 1993; Grosslight et al., 1991). Analysis of data from the elementary studies of this project (Kenyon et al., 2008) indicates that when constructing models, elementary students shifted from drawing illustrative pictures to developing more abstract explanatory diagrams. At the end of the modeling intervention, students constructed many more models that provided non-visible explanatory mechanisms and processes.

Consider again Figure 3, showing one student's models of how the water on a plate disappears and how water drops appear on a soda can. As mentioned earlier, the post-interview model (Figure 5) includes more explanatory features and text such as change over time, using arrows, and explaining how the water disappears from the plate and condenses on the soda can. When asked during the post-interview to explain the differences between the original and post-test model, the student explained:

With the Coke can, I think I drew a little bit better. And, I don't think the invisible water was an appropriate thing [in my initial model]. I didn't really show, it [my initial model] doesn't even show how it got there. It just says invisible water forming into a droplet. It doesn't really show how.

The student emphasized that the major difference between the two models had to do with showing the process that can account for what occurred in the phenomenon, a Level 2 perspective on what models should accomplish.

Additional analysis of the pre-test assessment for elementary students indicates that most students paid attention to capturing descriptive detail about the phenomenon. They did not focus on explanation or on the process underlying the phenomenon, but rather on depicting the phenomenon itself. In contrast, more students in the post-test used the term "explain" and talked about process. For example, one student stated in the pre-test, "[The models I drew] are helpful because it shows that the covered cup will stay the same and the uncovered cup will evaporate." In contrast, this student stated in the post-test, "The models are helpful because they explain how evaporation and condensation works...." (Kenyon et al., 2008).

Data from the elementary studies also indicate that some students used their models to explain related phenomena when they were prompted to do so, indicating some aspects of a Level 3 perspective. In response to the marker question mentioned above, for example, more students explicitly referred to their evaporation models in the prior assessment question and mapped the model to the real-world phenomenon in the post-test than the pre-test ( $41 \%$ vs. $16 \%$ ). Similar results are seen when students are asked to apply the class "consensus model" to explain how a solar still works. After instruction, they developed more sophisticated models of evaporation and used those models to make explanations and predictions about studied and new phenomena.

Thus, as the elementary students learned more about modeling evaporation and condensation phenomena, they incorporated more causal aspects into their models - moving from static veridical pictures to showing invisible processes and processes over time, and referring to both process and explanation in their interviews. Although it can be difficult to distinguish in some cases whether students produced Level 1 models because they simply lacked the relevant content knowledge (e.g., about evaporation) rather than having a less sophisticated view of modeling, the students' later reflections make clear that they learned the importance of including explanatory mechanisms in their scientific models. 


\section{Shifts among Generative Levels in the Middle School Students}

Focus group interviews with middle school students reveal that they developed along multiple aspects of the generative dimension. Analysis of interviews throughout the second unit of the middle school modeling curriculum indicates that even their initial models appeared to focus on explaining rather than merely illustrating phenomena, an important part of Level 2 performance in the generative dimension. The models constructed throughout the curriculum typically represented a non-visible process, such as showing light rays, "waves of odor," or "odor particles" moving, with accompanying labels and arrows to illustrate a process or time sequence. In interviews, these students spoke about models as communicating explanations and one's thinking to others-for example, to "show what you're talking about" and help "explain to the others." The recurrence of comments like these across different focus group conversations suggests students considered their models to have an audience, in contrast to typical school science in which answers are for the teacher (Jimenenez-Aleixandre et al., 2000; Lemke, 1990).

Somewhat later in the second unit, middle school students spoke about constructing models that were consistent with evidence and information about the phenomena, illustrating additional characteristics of Level 2. Interestingly, while many students expressed that models must be consistent with the "information" they had about the phenomena, they seemed to view this information as equivalent whether provided by a reading, a teacher, a peer, or an experiment. Thus, they appear to be treating information as unproblematic, not requiring interpretation or reconciling discrepant evidence. In this way, they may be viewing models as a type of "science answer," in which the school science task is to learn and report correct answers, without concern for whether particular facts were drawn from a textbook or from data.

By the end of the unit, students revealed a more sophisticated view of the model being consistent with the phenomenon. Students viewed their models as having to explain multiple aspects of the phenomena, rather than simply considering whether the model was consistent with the phenomenon, a view that demonstrates a progression to Level 3. For instance, students were able to discuss advantages of combining models that explained different aspects (air components in one model and particle movement in another):

Jenna: Well, I agree with Joe and Tim ... that they should combine both of the models because this model, Joe's model, it explains everything like the air, hydrogen, and everything that's in it. But this [alternative model] also shows how they look combined and how they move...

Kate: Everything is made up of atoms and molecules. So the gumdrop model and Sean's model is kind of showing the molecules and atoms that are in the air and in odors. And our phenomenon is how we smell things from a distance. ... The gumdrop model doesn't really show them moving around, but it shows the atoms and the different kinds of molecules. So then, eventually, you'd mix in some different kinds of molecules that have an odor in there. And then it'll kind of go along with the rest of the air and get to our nose... [Interview \#9, Lesson 15]

This excerpt illustrates how students recognized that there are multiple aspects of phenomena that need to be explained, and this may require multiple models, rather than a single answer. While the middle school students' performances were not consistent with all the aspects of this third level, there is some evidence of advances into aspects of these understandings.

Students were also able to use their current models to make predictions about closely related phenomena. In the following excerpt, the researcher poses a new situation, and two students discuss whether their model could be used to make predictions about a mixture of gases.

Researcher: Would you be able to predict what's going on with your model?

Sean: Well, you could predict how they move and what types of atoms are in the mixture and how the atoms form the molecules and ... maybe, because you could show how they mix together, kind of how they form... like odors and everything.

Kate: Yeah, ... probably, because it shows the odors kind of mixing together and all moving around, so you can kind of predict that all molecules and atoms are moving, and they are made up of ... atoms... [Interview \#8, Lesson 10] 
However, sometimes students struggled with using a model to make predictions. For example, in one conversation, two students suggested that "your model can be your best guess," while others disagreed, stating that "to make it accurate ... you can't really model it without knowing." Another student pointed out that "like your prediction," you can build a model representing "stuff that you think is true," and then "after you get the information you can make the model then." [Interview \#7, Lesson 8]

Taken together, these examples suggest that students are confident with predictions that apply the behavior of the phenomenon they already figured out. Some students appear to have an initial sense of generativity, in that models can include (perhaps temporarily) a prediction that can be tested, and then incorporate into the model. Nonetheless, students see these predictions as tentative that require evidence before being accepted into the model. We do not see indications of students drawing new implications from the model to attempt to discover new aspects of the phenomena. Thus, while we see the models being viewed generatively, in that they can be applied to new situations, attempting to use their model for predictions does not become part of raising questions to extend the model.

\section{Summary of Successes and Challenges in Models as Generative Tools}

Elementary and middle school students showed important successes in understanding and using models as generative tools for explaining phenomena. Students were able to draw on and guide their empirical investigations by representing their ideas as models and revising them as needed. Students used models to articulate the process or mechanism underlying phenomena, and moved beyond earlier approaches using models as descriptions. We also saw that they attended to the model's consistency with the phenomena and other aspects such as its ability to explain multiple aspects of a phenomenon. They also began to recognize that they could use their models to make predictions.

Nonetheless, there were several limitations in students' articulated reflections that indicated they did not achieve the highest levels of this dimension. First, the students still exhibited a "school science" view of accepting "information" from books, teachers, or empirical evidence, without distinguishing between them. For example, there was no mention of the need to interpret empirical evidence (Lederman, 2007), concern about needing empirical evidence to corroborate "information" from textbooks and simulations, or inclination to evaluate or explain "facts" from scientific authorities before just adding them to their models.

Another limitation was evident in students' views of the predictive power of models. While they were able to draw out predictions from their models, those cases were, not surprisingly, closely connected to what they had already observed and explained. There was no evidence students thought that they could reason with their model and derive new aspects of the behavior of the phenomenon, which could then be tested. One student supported this by stating, "The purpose for modeling is to be able to explain what you've learned so far... and what you think is what it's talking about."

Finally, another limitation concerned the perceived benefits of modeling for sensemaking and communication. Students saw models as useful ways to capture what they understood and communicate to others. They saw that understanding a model constructed by somebody else could help them learn more about a phenomenon. But there was little apparent consideration that constructing a model could help their own thinking about a scientific phenomenon, such as helping think through a phenomenon more rigorously or tease apart alternative ideas.

Clearly these elementary and middle school students had areas for further progress in their reflective practice around using models as generative tools. Yet the fact that they were better able to reflect the mechanisms underlying phenomena in their models, develop models consistent with multiple aspects of the phenomena, and recognize the need for comparing and revising models to create consensus, suggests the students are engaging with and understanding key aspects of this complex practice.

\section{Models Change as Understandings Improve}

The second dimension, models change as understandings improve, addresses the idea that scientific knowledge generated through models is dynamic - it is conjectural, testable, and revisable. This dimension reflects the understanding of the nature of science that scientific knowledge is tentative and subject to change (Lederman, 2007), with the scientific model as the representation of the scientific knowledge. This requires a more sophisticated view of the nature of scientific knowledge and the processes that construct it than the 
Table 4

A learning progression for understanding models as changeable entities

\begin{tabular}{ll}
\hline Level & Performances \\
\hline 4 & Students consider changes in models to enhance the explanatory power prior to obtaining evidence supporting \\
these changes. Model changes are considered to develop questions that can then be tested against evidence \\
from the phenomena. \\
Students evaluate competing models to consider combining aspects of models that can enhance the explanatory \\
and predictive power. \\
Students revise models in order to better fit evidence that has been obtained and to improve the articulation of \\
a mechanism in the model. Thus, models are revised to improve their explanatory power. \\
Students compare models to see how different components or relationships fit evidence more completely and \\
provide a more mechanistic explanation of the phenomena. \\
Students revise models based on information from authority (teacher, textbook, peer) rather than evidence \\
gathered from the phenomenon or new explanatory mechanisms. \\
Students make modifications to improve detail, clarity or add new information, without considering how the \\
explanatory power of the model or its fit with empirical evidence is improved. \\
Students do not expect models to change with new understandings. They talk about models in absolute terms of \\
right or wrong answers. \\
Students compare their models to assess, if they are good or bad replicas of the phenomenon. \\
$1 \quad$
\end{tabular}

simpler intuitive view of science as determining whether or not hypotheses are correct (Lehrer \& Schauble, 2006; Windschitl et al., 2008).

To capture different steps along this transition, we examine students' purposes for revising their models and how they evaluate and decide what to change about their models. This dynamic nature of models is shown in four levels (see Table 4). As with the generative dimension, each increasing level influences interacting aspects of the modeling practice, so two performances are indicated for each level. Students' progress through this dimension reflects an increasing understanding of the incremental nature of knowledge building, as well as the importance of improving the explanatory power of models and their fit with evidence. In the next sections, we describe each level and use examples from classroom work to support the feasibility of the types of performances, and consider changes learners exhibit as they are engaged in modeling practices.

\section{Empirical Illustrations of the Levels of Performance}

Level 1 indicates that students see models as unchangeable entities that can be compared with other models to assess if they are good or bad replicas of the phenomenon. Students do not expect models to change following their growing understanding, but rather see them as either right or wrong. For example, one elementary student illustrating aspects of this level stated, "With a model, ... you already know that is the right picture and that is the idea you should have." When asked, "Could you change that model [that illustrated something you investigated]?" another elementary student in the pre-interview responded, "No."

At Level 2, students recognize that models can be revised. However, students revise models to improve appearance or clarity, or to add detail and information from a convincing peer or from authority (e.g., the teacher or textbook). This is in contrast to using evidence from the phenomena or considering how the change will make the model a better explanation of the phenomena (e.g., illuminating non-visible mechanisms that can explain why the phenomenon occurs). Middle school students illustrate aspects of level 2 when they referred to understandability for evaluating their models:

I think you should compare models and see what parts of them are good, and you could change it. And you should choose the one that's easiest to read and you can probably explain what is going on by just looking at it.

In contrast, students illustrating aspects of Level 3 practice focus on improving the explanatory power in the model. They do so by improving the model's fit with the empirical evidence (e.g., by encompassing more aspects of observations about the phenomena) as well as adding explanatory mechanisms to better explain why something occurs. Thus, students at this level evaluate and attempt to improve consistency with 
evidence, completeness in accounting for multiple aspects of phenomena, and coherence in their explanations. For example, when a sixth-grader contrasted his initial model with his most recent revised model, he referred to using the idea of "open space" to improve his model:

... like the first model I drew about this was like-I only put dots that were showing the odor. But now, I put down the molecules, and I labeled the open space air because I learned that all the open space is air... [Interview \#1, Lesson 1]

At Level 4, students understand that models serve not only as tools that can explain patterns of data drawn from phenomena, but also as predictive tools that can be used to address "what if" questions and make hypotheses about how phenomena may behave. At this level, the two dimensions of generativity and dynamic are most closely related. Changes to models are considered prior to obtaining data. Students may compare and assess alternative components or relationships in competing models in order to combine their best aspects, maximizing their explanatory and predictive power. They also recognize that models can have different strengths, and therefore be appropriate for explaining different aspects of the phenomena. For example, a sixth-grader described why his group used multiple models, revealing some aspects of this level:

... we did more than one model because some of the models aren't able to show different parts of what's happening. So if you have the three models, then you can take each part of those and kind of like put them together to put a model together. And it's also just kind of to help you see different ways of what it's doing... [Interview \#5, Lesson 4]

\section{Shifts among Dynamic Levels in the Elementary Students}

We now examine whether and how elementary students progressed along this dimension. This aspect of the practice is indeed challenging and quite in conflict with students' conceptions of science and traditional schooling in which answers are static and to be simply learned. Students in traditional schooling are often reluctant to revise solutions to "solved problems" (Berland \& Reiser, 2009; Carey \& Smith, 1993; Gitomer \& Duschl, 1995). In general, we found that students showed some growth in this dimension of the practice, as they moved from unprincipled decisions about changes in their models to using criteria of accuracy and explanatory value in developing class consensus models. Furthermore, we found that some students moved from simply adding details to adding salient details that improved the explanation. As an example, in the excerpt below, a group of five students shares their individual models of evaporation to decide what should be included in their consensus model.

Jacob: All of our models show the same thing pretty much. This is the surface area of the soil that sucks in some water [pointing to his model]....

Fred: First of all, how can the soil suck up the water? [Looking at Jacob's model of water evaporating into the air and soil sucking up water.]

Chris: It doesn't suck it up.

Fred: Then why did he write it? It is the same thing I did. Sunlight goes into the water and evaporates into the air. That is pretty much it.

Chris: It doesn't just evaporate into the air.

Jacob: And you think yours is better why?...

Scott: His says more.

Fred: His says more, but it is wrong. First of all the soil doesn't suck up water.

Jacob: For the tenth time I know. [Jacob erases the water going into the soil.]

Fred: Okay, now that works. 
Scott: Jacob needs to get to the point... We are not really studying...

Melinda: We could add in some of Fred's.

Scott: This is what were are going to do, on our final thing we are not going to show that water actually goes into the ground cause we are studying on evaporation and not how it goes in the ground.

Here we see students attend to three evaluative criteria as they revise their models. Fred strongly focuses on the need to make the model scientifically accurate. Scott brings up a typical student-generated evaluative criterion, which is the importance of details in the model (it "says more"). Then, Scott emphasizes the importance of saliency and staying focused on what needs to be in the model. We see during this consensus modeling process that students realized that models are more than the right answer; modeling is an iterative process that can change their ideas and make them better using what they learned from their investigations.

Consistent with this understanding, students revised their models to fit data they collected or to include new ideas that provided more complete explanations. Students showed some success in the evaluative practice as they moved from unprincipled decisions in changing their models (e.g., more detail is better) to using these criteria of accuracy and explanatory value in developing consensus models. As mentioned earlier, the elementary students included more causal aspects in their models as the unit progressed, reflecting a shift from just adding more detail to adding salient detail that improves the explanation. Our findings suggest that many students progressed among levels with respect to understanding models as changeable entities.

\section{Shifts among the Dynamic Levels in the Middle School Students}

The middle school students also made progress in considering how and why models change, and exhibited some limitations in their reflective practice. In the focus groups, students frequently commented on the need for models to change. We saw a range of reported reasons for revising models.

First, students revised their models to improve their communicative aspects, reflecting a Level 2-type focus on communication. Students frequently mentioned improving the ability of models to communicate their ideas, suggesting that students viewed how effectively a model explained the phenomena as a criterion to assess the quality of models. In following excerpt, students refer to a good model as "easiest to read," where readers can "explain what they think is going on by just looking at it."

Researcher: ... How do you decide which [model] is good?...

Tiffany: The one that's easiest to read and you can probably explain what they think is going on by just looking at it and not having... to explain it.

Michelle: I agree with Tiffany. You'd pick the one that would be the easiest to explain and the one that had all the parts in it. [Interview \#5, Lesson 4]

A second reason mentioned by students for changing models was acquiring "new information," something learned from experiments, the teacher or from scientists' models. Early in the unit, students constructed models that included "how much information we know." Later in the unit, when students developed experiments and revised their models to construct class consensus models, "information" used to change models was associated with aspects of the phenomenon learned from those experiments. For example, in the following excerpt, students refer to having learned that "air has mass" and they would need to show that "air is something" rather than "empty space" in their models.

Karen: When we keep continuing in the chapters, we're probably going to learn something new, and we're going to probably add it in [to the model]. But we're still going to keep those ideas because we already know that those are true because of recent experiments and information that we've gotten...

Researcher: ... Would you modify ... your models with this information?

Karen: We learned during this [unit] that odor and air has mass so that in some way you could change it to show that those two have mass. 
Kate: I would change my model. . . like instead of making air empty space I would like shade it in to show that air is actually like something instead of just like blank space. [Interview \#6, Lesson 5]

At this point, students expected their model to change incrementally, building on "those ideas we already know" rather than replacing the prior models. The changes students considered were not cosmetic changes, but rather substantive changes to capture new aspects of understanding about the phenomena. The reason as articulated, however, is a somewhat simplistic view of information. Students appeared to have equated any authority such as a textbook or information from the teacher with primary data, and they did not talk about the need for data to be interpreted to determine its implications for the model. They also did not explicitly articulate how the new information (air has mass) helps the model explain the phenomenon of odor traveling. These shifts in the students' thinking about changing models suggests progress toward Level 3, a deeper understanding of the role of evidence and new ideas as underlying reasons to change models, yet with some limitations in their views of evidence and explanatory power.

A third reason students revised their models was to reflect useful new ideas or representations emerging from the process of comparing models. Comparing and assessing alternatives in competing models in order to enhance the explanatory and predictive power is central to Levels 3 and 4 of the progression. Students saw comparing models as leading to changes because comparing models is useful "to see how people are thinking." These comparisons occurred typically during conversations to reach a consensus model:

Researcher: Can you specify what you have changed [in your model] ... In which way did Gretchen's drawing help you?

Stacy: She drew a smell with a bunch of dots, and she said they were really particles moving and stuff. So then-I didn't draw particles. I just drew a bunch of smell because I had no idea because that's what I pictured in my head. And then when she told me that, I pictured a bunch of particles moving in a little bubble of smell and odor, and it helped me understand a little more of what happens.

Kate: Yeah. In the second [model] I actually showed some arrows. The second one was where the air would be compressed. Karen didn't have any arrows in hers, and I agreed with hers. But then she realized that I had the movement for arrows. So then I realized that and I thought that there shouldn't be movement because the air is packed together so tightly that you can't move the plunger down anymore so the air shouldn't be able to move. [Interview \#5, Lesson 4]

Examples such as these, in which students consider components of other models (arrows to show movement) and their fit with the understanding of the phenomenon (the "packed together" air), indicate steps toward evaluating models for their ability to fit and explain phenomena.

Comparing competing models also allowed students to assess alternative components, thinking about useful parts of each. For example, in the following excerpt, Karen and Kate demonstrated some aspects of a Level 4 understanding, by justifying the advantage of combining models "to show different parts of what's happening...."

Researcher: Why are you modeling in three different ways?

Karen: Well, we did more than one model. We did three of them, and even more because some of the models aren't able to show different parts of what's happening. So if you have the three models, then you can take each part of those and kind of like put them together to put a model together. And it's also just kind of to help you see different ways of what it's doing. [Interview \#8, Lesson 10]

This idea was also reflected in the earlier example [Interview \#9, Lesson 15], in which Jenna and Kate talked about combining two models, because one model (the gumdrop model) is better at showing the components of the air, while another is better at showing movement of particles.

In sum, middle school students' reflective practice revealed that they understood models as dynamic entities that can and should be revised. The students' reasons for revising models seemed linked to gathering evidence and learning more about the phenomena, and indicated some steps toward seeing models as 
improving based on their ability to "show how" or explain why phenomena occur. However, we did not see a clear articulation of criteria for assessing models, other than the clarity in communicating or the need for models to be accurate regarding their consistency with the phenomenon.

\section{Summary of Successes and Challenges in Models Change as Understandings Improve}

We would expect from the research literature that students may think of scientific ideas, including models, as fixed correct or incorrect answers, rather than as ideas that can be incrementally improved (Carey \& Smith, 1993; Hogan \& Corey, 2001). However, we found that with sufficient support, students were able to revise their models and explain how their models were improved from their earlier versions, referring to increasingly sophisticated criteria. Students readily revised models in order to improve their accuracy and explained their changes in these terms. Middle school students also talked about the need for models to be easily comprehensible. Such changes exemplify a shift from Level 1 to Level 2 of the construct map.

We also saw a subtle increase in sophistication in how students talked about the reasons for revising models, shifting from focusing solely on "accuracy" to discussing how well the model explained the phenomena (e.g., the elementary student's critique of his earlier model that "doesn't even show how it [the water] got there"). Middle school students also talked about improving models so that they can explain more of the phenomenon, combining the best of two competing models. While not representing all aspects of Level 3, it appears that some of the middle school students made steps toward aspects of these understandings.

We did not see examples of students' reflective practice at Level 4. At this level, we would expect students to explore improving their models in advance of getting data that make the model problematic. For example, students might consider what is known about an additional factor not yet considered in their model, and add that factor to their own model, thus creating hypotheses that could be tested empirically. While this may be viewed as ambitious for a classroom science setting, nevertheless this represents an important understanding about models that we may want to try to help students uncover and experience in their own practice.

\section{Discussion and Conclusion}

Our goal in this research is to examine what aspects of the complex practice can be made accessible and meaningful for students in the elementary and middle grades, and where the challenges emerge. To that end, we have presented two dimensions we suggest can capture many of the important connections between the elements of modeling practice and the underlying knowledge that makes it meaningful.

It is important to note that these initial studies, consistent with a number of prior explorations of modeling (Acher et al., 2007; Lehrer \& Schauble, 2004, 2006; Schwarz \& White, 2005) suggest that core elements of the practice appear to be tractable for both the elementary and middle grades students. Students were able to construct models that were abstracted to some extent from the specifics of the phenomena they studied, and captured important explanatory mechanisms and relationships between the components (e.g., water particles moving from liquid to gas, odor particles in motion, colliding with air particles). Students were able to use models to make predictions about closely related phenomena, drawing directly on the explanations captured in the models to make predictions for a new situation. They were able to evaluate and compare models and determine which aspects to include in a consensus model. Finally, they were able to revise their models when learning more about the phenomena, and constructed multiple models that successively increased in sophistication. Furthermore, there is initial evidence that students were developing some aspects of the important understandings about this practice. Nonetheless, there are some challenges associated with progress along these dimensions of practice that can inform future work in refining these learning progressions.

Some of the challenges in cultivating sophisticated scientific practices arise from the influences of the existing culture of "school science" (Berland \& Reiser, 2009; Hogan \& Corey, 2001; Jimenenez-Aleixandre et al., 2000). Bringing new routines from a curriculum, even with appropriate teacher support around these activities, does not automatically create a meaningful practice. Practices are more than arbitrary routinesthey are meaningful due to the beliefs, understandings, motivations, and expectations that underlie them. Existing expectations about traditional schooling are at odds with important aspects of scientific practices. Viewing a discipline as fixed answers to be learned and reported rather than debated is at odds 
with evidence-based knowledge building. Reform-based curriculum materials and instructional designs face the challenges posed by students' (and teachers') existing beliefs and expectations about both learning and the discipline itself. Attempts to shift classroom culture toward scientific practice (or, indeed, any disciplinary practice) may result in attitudes, expectations, and beliefs arising from traditional schooling, on the one hand, with the nascent understandings associated with the disciplinary practice itself (Berland \& Reiser, 2009; Hogan \& Corey, 2001).

Several challenges emerge in attempting to cultivate modeling practices in classrooms. First, students need an authentic reason for building a model other than "doing school." Scientists create a model to help their own thinking and share their ideas with peers to test whether they are convincing in the professional community. In the case of our classroom materials, students are typically told when to create models, and their utility, if apparent, needs to emerge as they are used in their subsequent work. A second challenge emerges in giving students a real sense of audience for their models. On this front, we were partially successful, in that students reported the benefit of hearing their peers' ideas as models rather than just through open discussion. However, for the most part, students seemed to see their own models as being created for the teacher as just another form of "science answer." They did not typically try to make a model to facilitate their own thinking or their own communication of ideas. A third challenge is in motivating the need to revise models. While students saw the point of making partial answers more complete or more correct, as with constructing models, the class was always told to revise their models. This effectively took the decisions about when their models were sufficient and when they need to be revised out of the students' hands.

A related set of challenges emerges in grounding the metaknowledge directly on students' experience. While comprehensibility is a relatively common criterion for judging one's work, ideas like predictive power and parsimony that are typically applied to models are more sophisticated, and do not arise from the same everyday experiences. An important aspect of designs to support disciplinary practices is to provide situations that "create a need" for the particular disciplinary idea (Berland \& Reiser, 2009; Edelson, 2001; Lehrer \& Schauble, 2006). For example, one possibility for helping students understand what aspects of models are important to evaluate would be to engineer situations in which students are working with candidate models from others and having more trouble understanding one model than another. In addition, students might try to use someone else's model (or their own) to explain an unknown phenomenon, and then unexpectedly uncover limitations in the model. Students might try to use different models to make predictions or develop explanations, and observe tradeoffs in the models' utility, noticing that one model is more useful in one situation than another. We are not suggesting that encountering situations like these is necessary for making some progress in mastering the processes of modeling, but if we aim to have learners engage in meaningful practice, where they understand and appropriate the goals of the practice, these types of situations in which students experience the problems and then the utility of various solutions may be an important component of instruction.

Finally, we return to the framing question of creating a learning progression for a scientific practice. There has been much interest in the idea of creating learning progressions that would capture a coherent incremental trajectory. Some theoretical and methodological challenges arise when developing a learning progression for a practice rather than an aspect of scientific understanding, such as the nature of matter (Smith et al., 2006). One particular challenge is the integration of the performance of the practice with underlying metaknowledge. We have chosen to attempt to assess the combination of practice and knowledge, so as to avoid teaching and assessing routine procedures on the one hand, or decontextualized understandings about science on the other hand. However, doing so makes more complex the grain size of elements in a construct map, and the associated analytical tools for analyzing student work and discourse. A second and related issue is that metaknowledge does not consist of isolated disconnected fragments. The various aspects of what we understand about a practice interact. For example, understanding how to evaluate a model is clearly influenced by understanding why models are initially created and how they are used to develop knowledge. Understanding how and why models change (our second dimension) is clearly connected to understanding how models provide useful explanations about scientific phenomena (our first dimension). We have attempted to balance these challenges against the benefit of being able to track and assess reflective practice. We have argued for two dimensions that each combine elements of practice and aspects of metaknowledge. We suggest these dimensions are relatively discernable in students' reflections and in their performances, 
despite their clear influence on one another. In future work, we will explore both more fine-grained changes in students practices, as well as longer term longitudinal changes, in order to further evaluate the utility of these theoretical constructs in characterizing this scientific practice.

\title{
Acknowledgments
}

\begin{abstract}
This research was funded by the National Science Foundation under Grant ESI-0628199 to the MoDeLS project at Northwestern University, and grants ESI-0439352 and ESI-0439493 to the IQWST project at University of Michigan and Northwestern University. The opinions expressed herein are those of the authors and not necessarily those of the NSF. For more information see http:// www.models.northwestern.edu.models
\end{abstract}

\section{References}

AAAS. (1993). Benchmarks for science literacy. New York, NY: Oxford University Press.

Abd-El-Khalick, F., BouJaoude, S., Duschl, R., Lederman, N.G., Mamlok-Naaman, R., Hofstein, A., et al. (2004). Inquiry in science education: International perspectives. Science Education, 88(3), 397-419.

Acher, A., Arcà, M., \& Sanmartí, N. (2007). Modeling as a teaching learning process for understanding materials: A case study in primary education. Science Education, 91(3), 398-418.

Berland, L.K., \& Reiser, B.J. (2009). Making sense of argumentation and explanation. Science Education, 93(1), 26-55.

Carey, S., \& Smith, C. (1993). On understanding the nature of scientific knowledge. Educational Psychologist, 28(3), 235-251.

Duschl, R.A., Schweingruber, H.A., \& Shouse, A.W. (Eds.), (2007). Taking science to school: Learning and teaching science in grades K-8. Washington, DC: National Academies Press.

Edelson, D.C. (2001). Learning-for-use: A framework for integrating content and process learning in the design of inquiry activities. Journal of Research in Science Teaching, 38(3), 355-385.

Fortus, D., Krajcik, J., Dershimer, R.C., Marx, R.W., \& Mamlok-Naaman, R. (2005). Design-based science and real-world problem-solving. International Journal of Science Education, 27(7), 855-879.

Gitomer, D.H., \& Duschl, R.A. (1995). Moving toward a portfolio culture in science education. In S.M. Glynn \& R. Duit (Eds.), Learning science in the schools: Research reforming practice (pp. 299-326). Mahwah, NJ: Lawrence Erlbaum Associates.

Grosslight, L., Unger, C., Jay, E., \& Smith, C.L. (1991). Understanding models and their use in science: Conceptions of middle and high school students and experts. Journal of Research in Science Teaching, 28, 799-822.

Harrison, A.G., \& Treagust, D.F. (2000). A typology of school science models. International Journal of Science Education, 22(9), 1011-1026.

Henze, I., Van Driel, J., \& Verloop, N. (2007). The change of science teachers' personal knowledge about teaching models and modelling in the context of science education reform. International Journal of Science Education, 29(15), 1819-1846.

Hogan, K., \& Corey, C. (2001). Viewing classrooms as cultural contexts for fostering scientific literacy. Anthropology \& Education Quarterly, 32(2), 214-243.

Jimenenez-Aleixandre, M.P., Rodriguez, A.B., \& Duschl, R.A. (2000). "Doing the lesson" or "doing science": Argument in high school genetics. Science Education, 84, 757-792.

Justi, R.S., \& Gilbert, J.K. (2002). Science teachers' knowledge about and attitudes towards the use of models and modelling in learning science. International Journal of Science Education, 24(12), 1273-1292.

Kenyon, L.O., Schwarz, C.V., Hug, B., \& Baek, H. (2008). Incorporating modeling into elementary students' scientific investigations. Paper presented at the annual meeting of the National Association for Research in Science Teaching, Baltimore, MD.

Krajcik, J., McNeill, K.L., \& Reiser, B.J. (2008). Learning-goals-driven design model: Developing curriculum materials that align with national standards and incorporate project-based pedagogy. Science Education, 92(1), 1-32. 
Lederman, N.G. (2007). Nature of science: Past, present, and future. In S.K. Abell \& N.G. Lederman (Eds.), Handbook of research on science education (pp. 831-879). Mahwah, NJ: Lawrence Erlbaum Associates.

Lehrer, R., \& Schauble, L. (2004). Modeling natural variation through distribution. American Educational Research Journal, 41(3), 635-679.

Lehrer, R., \& Schauble, L. (2006). Scientific thinking and science literacy: Supporting development in learning in contexts. In W. Damon, R.M. Lerner, K.A. Renninger, \& I.E. Sigel (Eds.), Handbook of child psychology (6th ed., Vol. 4). Hoboken, NJ: John Wiley and Sons.

Lemke, J.L. (1990). Talking science: Language, learning, and values. J. Green (Ed.), Language and educational processes. Norwood, NJ: Ablex.

Lesh, R., \& Doerr, H.M. (2000). Symbolizing, communicating, and mathematizing: Key components of models and modeling. In P. Cobb, E. Yackel, \& K. McClain (Eds.), Symbolizing and communicating in mathematics classrooms: Perspectives on discourse, tools, and instructional design (pp. 361-383). Mahwah, NJ: Lawrence Erlbaum Associates.

Lesh, R., \& Doerr, H.M. (2003). Foundations of models and modeling perspective on mathematics teaching, learning, and problem solving. In R. Lesh \& H.M. Doerr (Eds.), Beyond constructivism: Models and modeling perspectives on mathematics problem solving, learning, and teaching (pp. 3-33). Mahwah, NJ: Erlbaum.

Schwarz, C.V. (2002). Is there a connection? The role of meta-modeling knowledge in learning with models. In P. Bell, R. Stevens, \& T. Satwicz (Eds.), Keeping learning complex: The Proceedings of the Fifth International Conference of the Learning Sciences (ICLS). Mahwah, NJ: Erlbaum.

Schwarz, C.V., \& Gwekwerere, Y.N. (2007). Using a guided inquiry and modeling instructional framework (EIMA) to support preservice K-8 science teaching. Science Education, 91(1), 158-186.

Schwarz, C.V., \& White, B.Y. (2005). Metamodeling knowledge: Developing students' understanding of scientific modeling. Cognition and Instruction, 23(2), 165-205.

Shwartz, Y., Weizman, A., Fortus, D., Krajcik, J., \& Reiser, B.J. (2008). The IQWST experience: Using coherence as a design principle for a middle school science curriculum. Elementary School Journal, 109(2), 199-219.

Smith, C.L., Wiser, M., Anderson, C.W., \& Krajcik, J. (2006). Implications of research on children's learning for standards and assessment: A proposed learning progression for matter and the atomic molecular theory. Measurement, 4(1-2), 1-98.

Snir, J., Smith, C.L., \& Raz, G. (2003). Linking phenomena with competing underlying models: A software tool for introducing students to the particulate nature of matter. Science Education, 87(6), 794-830.

Spitulnik, M.W., Krajcik, J., \& Soloway, E. (1999). Construction of models to promote scientific understanding. In W. Feurzeig \& N. Roberts (Eds.), Modeling and simulation in science and mathematics education (pp. 70-94). New York: Springer-Verlag.

Stewart, J., Cartier, J.L., \& Passmore, C.M. (2005). Developing understanding through model-based inquiry. In M.S. Donovan \& J.D. Bransford (Eds.), How students learn (pp. 515-565). Washington, DC: National Research Council.

Tabak, I., \& Reiser, B.J. (2008). Software-realized inquiry support for cultivating a disciplinary stance. Pragmatics and Cognition, 16(2), 307-355.

Weizman, A., \& Fortus, D. (2007). Using scientific models to learn about shadows. Paper presented at the annual meeting of the National Association of Research in Science Teaching, New Orleans, LA.

Wilensky, U., \& Reisman, K. (2006). Thinking like a wolf, a sheep, or a firefly: Learning biology through constructing and testing computational theories-An embodied modeling approach. Cognition and Instruction, 24(2), 171-209.

Wilson, M. (2005). Constructing measures: An item response modeling approach. Mahwah, NJ: Lawrence Erlbaum Associates.

Windschitl, M., Thompson, J., \& Braaten, M. (2008). Beyond the scientific method: Model-based inquiry as a new paradigm of preference for school science investigations. Science Education, 92(5), $941-$ 967. 